\title{
Risk of symptomatic dengue for foreign visitors to the 2014 FIFA World Cup in Brazil
}

\author{
Eduardo Massad ${ }^{1,2}$, Annelies Wilder-Smith ${ }^{3}$, Raphael Ximenes', Marcos Amaku', \\ Luis Fernandez Lopez ${ }^{1,5,6}$, Francisco Antonio Bezerra Coutinho', ${ }^{1,6}$, Giovanini Evelim Coelho \\ Jarbas Barbosa da Silva Jr ${ }^{7}$, Claudio José Struchiner ${ }^{8}$, Marcelo Nascimento Burattini ${ }^{1,6,9 /+}$
}

\author{
${ }^{1}$ LIM01-Hospital de Clínicas, Faculdade de Medicina ${ }^{4}$ Faculdade de Medicina Veterinária \\ ${ }^{6}$ Núcleo de Análises Interdisciplinares em Políticas Públicas e Estratégia, Universidade de São Paulo, São Paulo, SP, Brazil \\ ${ }^{2}$ London School of Hygiene and Tropical Medicine, London, UK ${ }^{3}$ Lee Kong Chian School of Medicine, Nanyang University, Singapore \\ ${ }^{5}$ Center for Internet Augmented Resercha \& Assesssment, Florida International University, Miami, FL, USA ${ }^{7}$ Ministério da Saúde, \\ Brasília, DF, Brazil ${ }^{8}$ Programa de Computação Científica-Fiocruz, Rio de Janeiro, RJ, Brazil ${ }^{9}$ Hospital São Paulo, \\ Escola Paulista de Medicina, Universidade Federal de São Paulo, São Paulo, SP, Brazil
}

Brazil will host the FIFA World Cup ${ }^{\mathrm{TM}}$, the biggest single-event competition in the world, from June 12-July 13 2014 in 12 cities. This event will draw an estimated 600,000 international visitors. Brazil is endemic for dengue. Hence, attendees of the 2014 event are theoretically at risk for dengue. We calculated the risk of dengue acquisition to non-immune international travellers to Brazil, depending on the football match schedules, considering locations and dates of such matches for June and July 2014. We estimated the average per-capita risk and expected number of dengue cases for each host-city and each game schedule chosen based on reported dengue cases to the Brazilian Ministry of Health for the period between 2010-2013. On the average, the expected number of cases among the 600,000 foreigner tourists during the World Cup is 33, varying from 3-59. Such risk estimates will not only benefit individual travellers for adequate pre-travel preparations, but also provide valuable information for public health professionals and policy makers worldwide. Furthermore, estimates of dengue cases in international travellers during the World Cup can help to anticipate the theoretical risk for exportation of dengue into currently non-infected areas.

Key words: dengue - risk - foreign travellers - probabilistic - modelling - World Cup

The FIFA World Cup ${ }^{\mathrm{TM}}$ is the biggest single-event sporting competition in the world, attracting visitors from around the globe. Brazil will host the 2014 FIFA World Cup. To be held from June 12-July 132014 in 12 cities (Supplementary data, Fig. 1), Brazil is expecting to draw an estimated 600,000 international visitors in addition to more than two million domestic visitors (fifa. com/aboutfifa/worldcup/).

Brazil is endemic for dengue (Coelho et al. 2008, Murray et al. 2013). Dengue virus (DENV) was reintroduced into Brazil in 1981 and by 1995 it had spread throughout the country (Nogueira et al. 2007, Teixeira et al. 2009, 2013). Up until 2009, approximately five million cases of dengue caused by serotypes DENV-1, DENV-2 and DENV-3 were officially reported. In 2010,

\footnotetext{
doi: 10.1590/0074-0276140133

Financial support: FNS-SVS, MS, CNPq, LIM01-HCFMUSP, FAPESP, MS (27835/2012), DengueTools/Seventh Framework Programme of the European Community (282589)

+ Corresponding author: mnburatt@usp.br

Received 16 April 2014

Accepted 17 April 2014
}

DENV-1 predominated and in 2011 DENV-4 invaded the country such that, in 2013, the year with the highest dengue incidence reported so far, $95 \%$ of cases were due to DENV-1 and DENV-4 (dtr2004.saude.gov.br/sinanweb/ tabnet/dh?sinannet/dengue/bases/denguebrnet.def). According to the Brazilian Ministry of Health, in the first 14 weeks of 2014 , a reduction greater than $80 \%$ in the number of cases with respect to 2013 has been observed in the country (g1.globo.com/bemestar/noticia/2014/03/ casos-de-dengue-caem-80-no-1-bimestre-de-2014-dizministerio.html).

In addition, approximately $95 \%$ of the serotypes that circulated in 2013 are DENV-1 and DENV-4. As the serotypes circulating in 2014 are the same, it should be expected that the risk for dengue in 2014 would be due to these two serotypes.

More detailed statistics on dengue cases per month in Brazil during 2008-2012 can be found from the Brazilian Ministry of Health (dtr2004.saude.gov.br/sinanweb/ tabnet/dh?sinannet/dengue/bases/denguebrnet.def).

GeoSentinel is a worldwide network of travel medicine providers that see ill returning travellers. Dengue is an increasingly encountered diagnosis on international travellers (Wilder-Smith \& Schwartz 2005, Schwartz et al. 2008, Leder et al. 2013) and was also the most frequent cause of systemic febrile illness in travellers to Brazil, re- 
ported in almost $6 \%$ of ill returning travellers from Brazil in a recent GeoSentinel analysis (Wilson et al. 2014).

According to a recent publication, addressing the risk of dengue in an incomplete form, attendees of the sports events in 2014 are at high risk for dengue (Hay 2013). Notwithstanding the importance of drawing the attention to this risk in view of the upcoming World Cup, more detailed analysis are necessary to avoid unnecessary distress among visitors, health authorities and economic losses.

Brazil is a vast country. There is strong seasonal variation of dengue in Brazil and the seasonal distribution is highly dependent on the location (Viana \& Ignotti 2013). Transmission in Brazil is most intense during February through May, hence the high season will have passed for the World Cup.

Knowledge of the risk at the 12 different locations of the World Cup in June and July 2014 is important to inform international football fans, tourists and health providers alike. Such risk estimates will not only benefit individual travellers for adequate pre-travel preparations, but also provide valuable information for public health professionals and policy makers. Furthermore, estimates of dengue cases in international travellers during the World Cup can help to anticipate the potential risk for exportation of dengue into currently non-infected areas.

We applied a probability calculus to estimate the individual risk of dengue acquisition in non-immune international travellers to Brazil depending on the football match schedules and locations and dates of such matches for June and July 2014.

We obtained the locations of the World Cup from FIFA and dengue incidence data from Brazilian Ministry of Health (dtr2004.saude.gov.br/sinanweb/tabnet/ dh?sinannet/dengue/bases/denguebrnet.def).

Supplementary data, Fig. 2 shows the map of Brazil with the 12 cities that will host the matches and the incidence of dengue in those cities at the time of the event (averaged over the period between 2010-2013).

We then calculated the per capita daily incidence (force of infection) of dengue for local residents of the host-cities, the expected number of travellers and the number of days and period of the year these visitors are expected to spend in each city, according to each one of the 32 different game schedules analysed (Supplementary data, Fig. 2).

Our calculations are based on the observed dengue outbreaks in Brazil in the last four years when the predominant serotypes circulating were DENV-1 and DENV-4, the same epidemiological scenario observed in the first 14 weeks of 2014. The risk for travellers, therefore, was calculated assuming that they will be subject to a force of infection similar to the ones estimated for the period between 2010-2013. In addition, the calculation assumes that travellers are subject to the same force of infection as local residents. This assumption will be discussed later in this paper.

We based our calculations on 32 possible schedules according to FIFA's official calendar. In each of those schedules, it is assumed that a visitor will follow his/ her team along the Cup. The calculation assumes that visitors attending the matches along his/her team schedule spend a certain number of days in each of the cities hosting the matches, depending on the historical tourist attractiveness of the city (Supplementary data, Fig. 2).

The data used in these estimations are available from the official databases of the Ministry of Health of Brazil, such as Brazilian National Health Reporting System (dtr2004.saude.gov.br/sinanweb/) and Computer Department of the Ministry of Health (2.datasus.gov.br/ DATASUS/index.php), and consists in the number of cases reported in each of the 52 epidemiological weeks of the year. We used only the cases reported in the period corresponding to the schedules considered (Supplementary data, Fig. 2), from 11 June until 14 July from 2010 until 2013. This period corresponds to the low season of dengue transmission in all of the cities hosting the matches. In some cities, however, like Natal and Fortale$\mathrm{za}$, dengue transmission is still active during this period, although in a much lower intensity than during the peak season. Data on the expected number of visitors was obtained from the Ministry of Tourism (copa2014.gov.br/ pt-br/tags/turistas-estrangeiros).

The forces of infection, defined as the per capita number of new dengue cases per day (Marques et al. 1994, Luz et al. 2003) estimated from the raw data for the period between 2010-2013 for each city hosting the matches, were obtained by fitting the raw data to continuous functions. From forces of infection $(\lambda)$ it is possible to estimate the expected number of cases among travellers in each city $(i)$ hosting the games $\left(D_{i}\right)$, according to:

$$
D_{i}=N_{i}\left[1-\exp \left(-\int_{t_{2}}^{t_{2}} \lambda_{i}(t) d t\right)\right],(i=1 \ldots 12)
$$

where $N_{i}$ is the expected number of foreign visitors per schedule in the period between days $t_{1}$ and $t_{2} . N_{i}$ was estimated assuming that approximately $20 \%$ of each stadium capacity (number of seats) will be occupied by foreigners and by adjusting these figures to the total number of foreign visitors expected for each city hosting the games, according to Ministry of Tourism (copa2014. gov.br/pt-br/tags/turistas-estrangeiros).

We also calculated the individual risk and the expected number of dengue cases for each one of the 32 game schedules shown in Supplementary data, Fig. 1. As in each game two teams belonging to two different schedules participate, we adjusted the calculation by dividing $N_{i}$ by 2 when estimating the expected number of dengue cases for each schedule.

The simulated scenarios - As mentioned above, we calculated the individual risk of dengue acquisition in each city hosting the matches. As we know the expected number of tourists visiting each city, it is possible to simulate several different schedules according to the official FIFA time-schedule for the matches. The eight groups of national teams competing at the World Cup contain four teams each, totalising 32 possible schedules. We assume that a given visitor will follow his/her national team along the games. We also assumed that the time 
spent in each city for each schedule is a function of the historical tourist attractiveness of each city.

In addition, we considered three different epidemiological scenarios for the calculations, namely, the bestcase scenario, the year with the lowest dengue incidence in the months of June and July of the years 2010-2013; the worst-case scenario (the year with the highest dengue incidence in the same period) and the average scenario, considering the mean incidence in the period considered.

Our estimations result in an expected number of dengue cases of 33 individuals among the expected 600,000 foreign visitors, ranging from 3 (best-case scenario) and 59 (worst-case scenario). This translates to an incidence during the period from 11 June to 14 July of about five cases per 100,000 visitors. The individual risk of dengue acquisition varied depending on the schedule and epidemiological scenario considered. It ranged from 1.4*10-6 (best-case scenario of schedule H4) to $7.1 * 10-4$ (worstcase scenario of schedule $\mathrm{C} 2$ ).

Our results are summarised in Supplementary data Tables I-III. Accordingly, the expected number of visitors and of dengue cases for each epidemiological scenario in the 12 cities hosting the games is show in Supplementary data, Table I, while the expected number of cases and the individual risk of dengue for each one of the 32 matches schedules analysed is available from Supplementary data, Table II. Finally, Supplementary data, Table III shows the number of reported dengue cases for each one of the 12 cities hosting the games, comparing the years of 2013 and 2014 for the first 14 epidemiological weeks.

The cities for which the majority of expected number of dengue cases will probably be Fortaleza and Rio de Janeiro due to the higher number of tourists and longer length of staying (tourists historically tend to spend the longest period in these cities).

One advantage of our approach is that individual visitors could approximately estimate their own risk based on length and location of stay, according to the chosen schedule. More importantly, however, our results allow public-health authorities to anticipate the preparedness necessary for each host city regarding both preventative measures to control dengue activity and the planning of health structure needed to attend the expected number of dengue cases. In addition, our results could also be helpful to international health authorities orient their citizens and anticipate the theoretical potential risk of dengue and other arthropod-borne infections importation for their countries (Massad et al. 2008, 2009, Massad \& Wilder-Smith 2009).

Our figures may be an overestimate as we based our calculations on the assumption that a World Cup foreign visitor to Brazil is subject to the same risk as local residents. However, sitting in the football stadium for most of the day and wandering around touristic places and beaches may mean less exposure to Aedes mosquitoes as compared to living in a peridomestic environment where Aedes mosquitoes breed in abundance. On the other hand, we based our calculations only on dengue cases that were reported to the Brazilian Ministry of Health, which may be an underestimation, given the known underreporting of dengue worldwide (1) (Wilder-Smith et al. 2010). Bhatt et al. (2013) suggests that only approximately $25 \%$ of the estimated total dengue infections would actually be symptomatic ("apparent" infection). However, their definition of apparent dengue is more comprehensive than those of traditional surveillance systems, which if applied in our case could overestimate the risk of dengue for visitors. Therefore, in this paper we deal only with symptomatic dengue infection, as traditional surveillance system report dengue occurrence worldwide.

There are some evidences that visitors to Brazil are likely to be subject to a risk of dengue infection that may be less than that the local residents suffer. For instance, data from the Brazilian Ministry of Tourism (dadosefatos.turismo.gov.br/dadosefatos/home.html) show that in 2008 there was one single case among the 350 thousands European tourists that visited Rio de Janeiro in that year (Ximenes \& Massad 2013). This corresponds to an individual risk of dengue of the order of $2^{*} 10^{-6}$. This should be compared with the risk of dengue for local residents, which for 2008 in Rio was $2 * 10^{-2}$. Hence, European tourists were subjected to a risk of dengue that was of the order of $10^{-4}$ less than that of local residents. For 2010, the reported number of European visitors to Rio de Janeiro summed up to three cases among 370 thousands visitors. This corresponds to a risk of about $6^{*} 10^{-6}$. For the local residents, however, the risk was $5^{*} 10^{-4}$, a difference of about $1.2 * 10^{-2}$. In comparison, we estimated an average individual risk of infection of $5^{*} 10^{-5}$, which seems higher than the above figures for visitors. However, our calculations are based on the risk of dengue estimated for a specific period of the year and for the 12 cities hosting the games. As it is not known the visit duration and epoch of the year those European visitors spent in Rio de Janeiro, it is difficult to make a reliable comparison.

Nevertheless, it is likely that the expected number of cases among non-immune football fans attending to the World Cup in Brazil will be less than the figures here calculated. In any case, it is best to have an upper bound of the risks than no estimation at all.

Our approach can also be applied to the Brazil Olympic Games, which will take place mainly in Rio de Janeiro, to be held August 5-21, 2016, followed by the summer Paralympics, 7-18 September (rio2016.com/en).

Furthermore, visitors who come to Brazil to watch the World Cup football games are likely to extend their stay in Brazil for more sightseeing and discovering the country. The risk of dengue will obviously increase the longer they stay in the country, depending on where the travel will take them. A recent analysis by GeoSentinel also provides information on diseases other than dengue that international travellers or World Cup visitors to Brazil need to be aware of (Wilson et al. 2014).

Estimating the number of dengue infections in international visitors to Brazil may also help anticipate the risk of importation of dengue into currently non-dengue endemic countries when the travellers return home. Travellers contribute to the spread of dengue globally which for example has led to the dengue outbreak in Europe in 2012, in the Island of Madeira (Portugal) (Wilder-Smith 
et al. 2014). Data on air passengers and air travel patterns may help identify risks for importation (Napoli et al. 2012, Sessions et al. 2013). The establishment of dengue in currently uninfected area will depend on the presence and density of Aedes mosquitoes. Assessing the likelihood of local transmission of these viruses into currently uninfected countries such as most of Europe depends on the number of viraemic person-days among air-travellers arriving in the European Union (Seyler et al. 2009).

Finally, the dengue number of cases observed in the first 14 weeks of 2014 is more than $80 \%$ lower than the same period in 2013. Many factors could explain this observation, in particular the huge epidemic that occurred in 2013 (the highest ever in Brazilian dengue history with more than 1.3 million cases) and the severe drought observed in the summer period of $2103 / 2014$. The latter factor has been previously reported in Brazil (Olívêr et al. 2014), when a significant negative correlation was observed between dengue cases and bushfires, a phenomenon strongly influenced by drought. In addition, important vector control measures were reinforced as a result of the huge outbreak in 2013. In any case, it is expected that the number of dengue cases among travellers visiting Brazil in the World Cup will be very low.

\section{REFERENCES}

Bhatt S, Gething PW, Brady OJ 2013, Messina JP, Farlow AW, Moyes CL, Drake JM, Brownstein JS, Hoen AG, Sankoh O, Myers MF, George DB, Jaenisch T, Wint GRW, Simmons CP, TW Scott, Farrar JJ, Hay SI. The global distribution and burden of dengue 2013. Nature 496: 504-507.

Coelho GE, Burattini MN, Teixeira MG, Coutinho FAB, Massad E 2008. Dynamics of the 2006/2007 dengue outbreak in Brazil. Mem Inst Oswaldo Cruz 103: 535-539.

Hay S 2013. Football fever could be a dose of dengue. Nature 503: 439.

Leder K, Torresi J, Brownstein JS, Wilson ME, Keystone JS, Barnett E, Schwartz E, Schlagenhauf P, Wilder-Smith A, Castelli F, von Sonnenburg F, Freedman DO, Cheng AC, Geo Sentinel Surveillance Network 2013. Travel-associated illness trends and clusters, 2000-2010. Emerg Infec Dis 19: 1049-1073.

Luz PM, Codeço CT, Massad E, Struchiner CJ 2003. Uncertainties regarding dengue modeling in Rio de Janeiro, Brazil. Mem Inst Oswaldo Cruz 98: 871-878.

Marques CA, Forattini OP, Massad E 1994. The basic reproduction number for dengue fever in São Paulo state Brazil: 1990-1991 epidemic. Trans R Soc Trop Med Hyg 88: 58-59.

Massad E, Behrens RH, Burattini MN, Coutinho FAB, Behrens B 2009. Modeling the risk of malaria for travelers to areas with stable malaria transmission. Malaria Journal 8: 296-303.

Massad E, Ma S, Burattini MN, Ye T, Coutinho FAB, Li WA 2008. The risk of Chikungunya fever in a dengue-endemic area. J Trav Med 15: 147-155.
Massad E, Wilder-Smith A 2009. Risk estimates of dengue in travellers to dengue endemic areas using mathematical models. J Travel Med 16: 191-193.

Murray NE, Quam MB, Wilder-Smith A 2013. Epidemiology of dengue: past, present and future prospects. Clin Epidemiol 5: 299-309.

Napoli C, Salcuni P, Pompa MG, Declich S, Rizzo C 2012. Estimated imported infections of Chikungunya and dengue in Italy, 2008 to 2011. J Travel Med 19: 294-297.

Nogueira RM, de Araujo JM, Schatzmayr HG 2007. Dengue viruses in Brazil, 1986-2006. Rev Panam Salud Publica 22: 358-363.

Olívêr L, Burattini MN, Coelho GE, Struchiner CJ, Massad E 2014. A negative correlation between dengue and bushfires in Brazil. J Environ Health 76: 66-67.

Schwartz E, Weld LH, Wilder-Smith A, von Sonnenburg F, Keystone JS, Kain KC, Torresi J, Freedman DO, GeoSentinel Surveillance Network 2008. Seasonality, annual trends and characteristics of dengue among ill returned travellers, 1997-2006. Emerg Infect Dis 14: 1081-1088.

Sessions OM, Khan K, Hou Y, Meltzer E, Quam M, Schwartz E, Gubler DJ, Wilder-Smith A 2013. Exploring the origin and potential for spread of the 2013 dengue outbreak in Luanda, Angola. Global Health Action 6: 21822.

Seyler T, Grandesso F, Le Strat Y, Tarantola A, Depoortere E 2009. Assessing the risk of importing dengue and Chikungunya viruses to the European Union. Epidemics 1: 175-178.

Teixeira MG, Costa M da C, Barreto F, Barreto ML 2009. Dengue: twenty-five years since reemergence in Brazil. Cad Saude Publica 25 (Suppl. 1): S7-S18.

Teixeira MG, Siqueira Jr JB, Ferreira GL, Bricks L, Joint G 2013. Epidemiological trends of dengue disease in Brazil (2000-2010): a systematic literature search and analysis. PLoS Negl Trop Dis 7: e2520.

Viana DV, Ignotti E 2013. The ocurrence of dengue and weather changes in Brazil: a systematic review. Bras J Epidemiol 16: 240-256.

Wilder-Smith A, Ooi EE, Vasudevan SG, Gubler DJ 2010. Update on dengue: epidemiology, virus evolution, antiviral drugs, and vaccine development. Curr Infect Dis Rep 12: 157-164.

Wilder-Smith A, Quam M, Rocklov J, Liu-Helmersson J, Sessions OM, Khan K 2014. The 2012 dengue outbreak in Madeira: exploring the origins. Euro Surveill 19: 8.

Wilder-Smith A, Schwartz E 2005. Dengue in travellers. $N$ Engl $J$ Med 353: 924-932.

Wilson ME, Chen LH, Han PV, Keystone JS, Cramer JP, Segurado A, Hale D, Jensenius M, Schwartz E, von Sonnenburg F, Leder $\mathrm{K}$ 2014. Illness in returned travellers from Brazil: the GeoSentinel experience and implications for the 2014 FIFA Wrold Cup and the 2016 Summer Olympics. Clin Infect Dis doi: 10.1093/ cid/ciu122.

Ximenes R, Massad E 2013. Study of risk of dengue for tourists in Rio de Janeiro during the FIFA Confederations Cup, Brazil 2013, using mathematical modelling, BIOMAT, Toronto, $45 \mathrm{pp}$. 
TABLE I

Expected number of visitors and dengue cases for each of the cities hosting the games

\begin{tabular}{lcc}
\hline City & $\begin{array}{c}\text { Expected visitors }^{a} \\
(\mathrm{n})\end{array}$ & $\begin{array}{c}\text { Expected dengue case }^{b} \\
\text { n (best-worst) }\end{array}$ \\
\hline $\mathrm{NT}$ & 44,952 & $6(2-9)$ \\
$\mathrm{FT}$ & 58,195 & $10(1-14)$ \\
$\mathrm{RJ}$ & 101,910 & $11(0-22)$ \\
$\mathrm{BH}$ & 36,788 & $3(0-8)$ \\
$\mathrm{RE}$ & 37,693 & $0(0-1)$ \\
$\mathrm{CB}$ & 20,740 & $2(0-4)$ \\
DF & 34,391 & $1(0-1)$ \\
SA & 57,855 & $0(0)$ \\
MN & 26,252 & $0(0)$ \\
SP & 101,150 & $0(0)$ \\
CT & 34,782 & $0(0)$ \\
PA & 35,343 & $0(0)$ \\
\hline Total & 607,051 & $33(3-59)$ \\
\hline
\end{tabular}

$a$ : source: Brazilian Tourism Institute; BH: Belo Horizonte; CB: Cuiabá; CT: Curitiba; DF: Brasília; FT: Fortaleza; MN: Manaus; NT: Natal; PA: Porto Alegre; RE: Recife; RJ: Rio de Janeiro; SA: Salvador; SP: São Paulo.

\section{TABLE II}

Expected number of dengue cases and individual risk of infection for each scenario considered according to the 32 schedules analysed

\begin{tabular}{|c|c|c|}
\hline Schedule & $\begin{array}{l}\text { Expected cases } \\
\mathrm{n} \text { (best-worst) }\end{array}$ & $\begin{array}{l}\text { Individual risk } \\
\text { of dengue }\end{array}$ \\
\hline A1 & $4(0-3)$ & $3.35(0.28-5.79) * 10^{-4}$ \\
\hline A2 & $1(0-1)$ & $1.82(0.26-2.76) * 10^{-4}$ \\
\hline A3 & $2(0-2)$ & $3.42(0.69-5.34) * 10^{-4}$ \\
\hline A4 & $1(0-1)$ & $2.24(0.76-3.31) * 10^{-4}$ \\
\hline B1 & $2(0-3)$ & $3.09(0.15-4.93) * 10^{-4}$ \\
\hline B2 & $0(0-1)$ & $5.94(0.48-14.3)^{*} 10^{-5}$ \\
\hline B3 & $1(0-3)$ & $2.31(0.16-5.03) * 10^{-4}$ \\
\hline B4 & $0(0-1)$ & $7.76(1.44-21.8)^{*} 10^{-5}$ \\
\hline $\mathrm{C} 1$ & $2(0-4)$ & $3.75(0.36-6.63) * 10^{-4}$ \\
\hline $\mathrm{C} 2$ & $2(0-3)$ & $4.46(1.01-7.11) * 10^{-4}$ \\
\hline C3 & $1(0-1)$ & $1.45(0.35-2.06) * 10^{-4}$ \\
\hline $\mathrm{C} 4$ & $1(0-2)$ & $2.78(0.96-4.63)^{*} 10^{-4}$ \\
\hline D1 & $2(0-3)$ & $3.88(0.79-6.25) * 10^{-4}$ \\
\hline D2 & $2(0-3)$ & $2.92(0.21-5.51) * 10^{-4}$ \\
\hline D3 & $0(0-1)$ & $9.39(1.62-21.0)^{*} 10^{-5}$ \\
\hline D4 & $1(0-1)$ & $1.98(0.66-3.16) * 10^{-4}$ \\
\hline E1 & $1(0-1)$ & $1.41(0.26-2.44) * 10^{-4}$ \\
\hline E2 & $1(0-2)$ & $1.62(0.18-2.77) * 10^{-4}$ \\
\hline E3 & $1(0-1)$ & $1.15(0.03-2.29) * 10^{-4}$ \\
\hline E4 & $0(0)$ & $3.69(1.12-8.15) * 10^{-5}$ \\
\hline F1 & $2(0-4)$ & $3.314(0.17-6.25) * 10^{-4}$ \\
\hline $\mathrm{F} 2$ & $2(0-3)$ & $2.25(0.15-5.42) * 10^{-4}$ \\
\hline F3 & $0(0-1)$ & $6.67(0.42-15.8)^{*} 10^{-5}$ \\
\hline $\mathrm{F} 4$ & $0(0)$ & $5.27(0.91-13.3)^{*} 10^{-5}$ \\
\hline G1 & $1(0-2)$ & $1.80(0.11-3.04)^{*} 10^{-4}$ \\
\hline G2 & $0(0)$ & $5.26(1.84-8.13)^{*} 10^{-5}$ \\
\hline G3 & $2(0-2)$ & $3.78(0.87-5.38) * 10^{-4}$ \\
\hline G4 & $1(0-1)$ & $2.51(0.83-3.88)^{*} 10^{-4}$ \\
\hline H1 & $1(0-3)$ & $2.17(0.11-4.39)^{*} 10^{-4}$ \\
\hline $\mathrm{H} 2$ & $0(0-1)$ & $8.18(0.46-21.1)^{*} 10^{-5}$ \\
\hline H3 & $1(0-2)$ & $1.88(0.11-3.89)^{*} 10^{-4}$ \\
\hline H4 & $0(0-1)$ & $7.24(0.14-19.0)^{*} 10^{-5}$ \\
\hline
\end{tabular}


TABLE III

Reported dengue cases in the first 14 weeks of 2013 and 2014

\begin{tabular}{|c|c|c|c|}
\hline & 2013 & 2014 & $\begin{array}{c}\text { Variation } \\
(\%)\end{array}$ \\
\hline $\mathrm{CB}$ & 1,945 & 177 & 9.1 \\
\hline FT & 3,308 & 1,168 & 35.3 \\
\hline NT & 678 & 294 & 43.4 \\
\hline RE & 65 & 73 & 112.5 \\
\hline SA & 766 & 1,362 & 177.8 \\
\hline $\mathrm{MN}$ & 10,321 & 1,516 & 14.7 \\
\hline RJ & 41,165 & 1,278 & 3.1 \\
\hline PA & 741 & 120 & 16.2 \\
\hline $\mathrm{CT}$ & 553 & 177 & 32 \\
\hline SP & 6,945 & 7,550 & 108.7 \\
\hline $\mathrm{BH}$ & 74,860 & 4,849 & 6.5 \\
\hline DF & 5,107 & 4,532 & 88.7 \\
\hline Total & 148,467 & 25,110 & 16.9 \\
\hline
\end{tabular}

BH: Belo Horizonte; CB: Cuiabá; CT: Curitiba; DF: Brasília; FT: Fortaleza; MN: Manaus; NT: Natal; PA: Porto Alegre; RE: Recife; RJ: Rio de Janeiro; SA: Salvador; SP: São Paulo. 


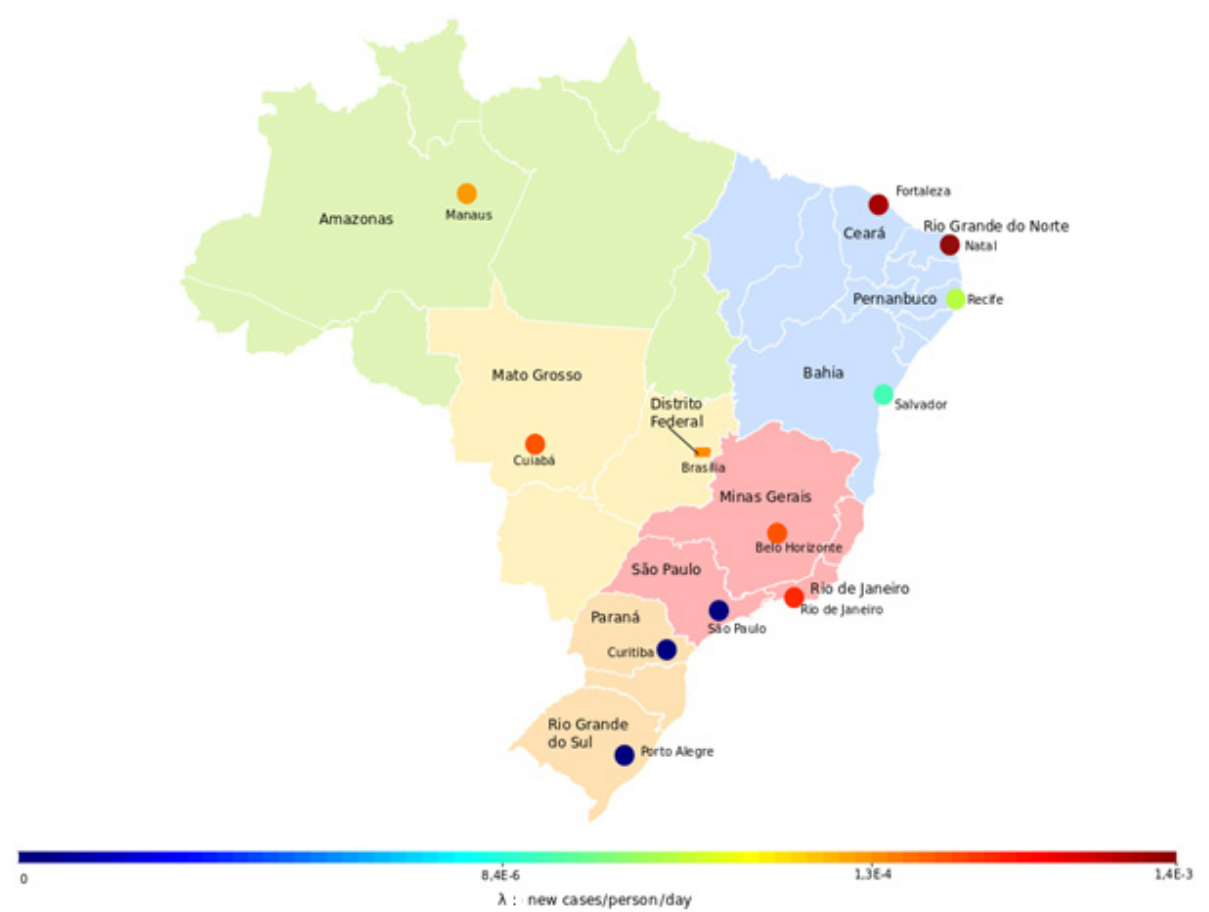

Fig. 1: cities that will host the 2014 FIFA World Cup and the respective forces of infection $(\lambda)$ averaged over the years between $2010-2013$ for the period of the games (12 June-14 July).

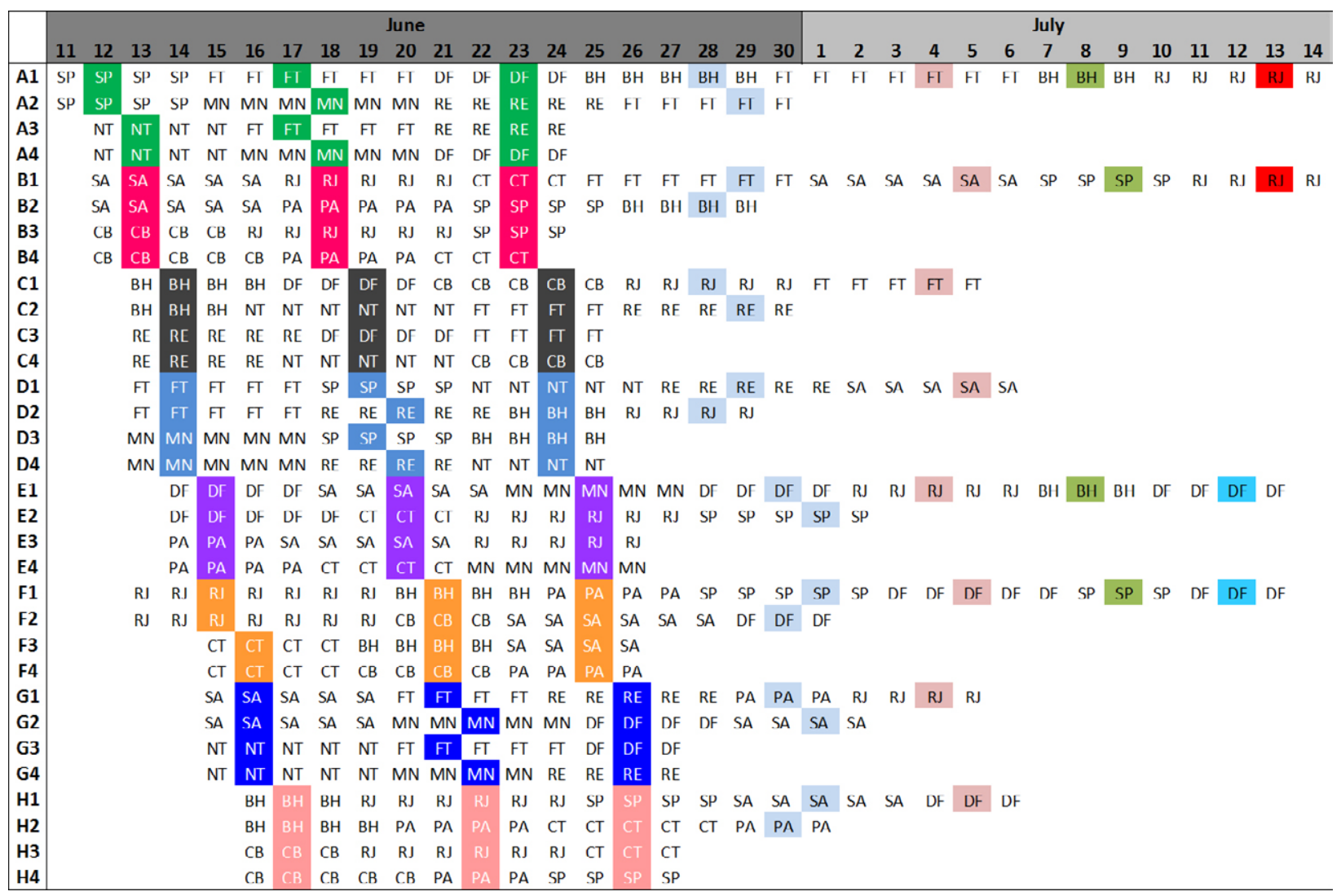

Fig. 2: the 32 matches' schedules chosen for the estimating the expected number of cases. Colours refer to the matches' groups and are marked on the specific dates of each match. BH: Belo Horizonte; CB: Cuiabá; CT: Curitiba; DF: Brasília; FT: Fortaleza; MN: Manaus; NT: Natal; PA: Porto Alegre; RE: Recife; RJ: Rio de Janeiro; SA: Salvador; SP: São Paulo. 